\title{
Downregulation of keratins 8, 18 and 19 influences invasiveness of human cultured squamous cell carcinoma and adenocarcinoma cells
}

\author{
A. UCHIUMI, M. YAMASHITA and Y. KATAGATA \\ Department of Molecular and Life Science, Faculty of Agriculture and Life Science, \\ Hirosaki University, Hirosaki, Aomori 036-8561, Japan
}

Received September 23, 2011; Accepted November 17, 2011

DOI: $10.3892 /$ etm.2011.413

\begin{abstract}
Keratin (K) expression index has been reported to be related to cell invasion activity in adenocarcinoma. In a previous study, we observed a negative correlation between $\mathrm{K}$ expression and cell invasion activity; i.e., when many Ks are expressed in the cells, the cell activity is low. To further elucidate the correlation between Ks and invasion activity, RNA interference experiments of K8, K18 and K19 were carried out to clarify the essential role of Ks using T24 and HEC-1 as typical squamous cell carcinoma and adenocarcinoma cells, respectively. K8 small interfering RNA (siRNA) was most effective against K18 and K19 expression and demonstrated the strongest effect on relative invasion activity among the siRNAs used. These results suggest that $\mathrm{K} 8 / \mathrm{K} 18$ or K8/K19 filaments may play roles in internal cell structure and invasion activity. Moreover, K18 and K19 were capable of substituting for each other, and K18 or K19 formed filaments with K8. In addition, cells treated with K8 siRNA demonstrated high invasion activity, which was approximately double that observed with control siRNA in HEC-1 cells. The order of effects was K8>K19>K18 in the two cell lines. The above results suggest that K8 may play a signifiant role in invasive functions in epithelial and metastatic cells.
\end{abstract}

\section{Introduction}

As inferred from the developmental origins of epithelial tissues, keratins (Ks) may be expressed in adenocarcinoma

Correspondence to: Dr Yohtaro Katagata, Department of Molecular and Life Science, Faculty of Agriculture and Life Science, Hirosaki University, 3 Bunkyocho, Hirosaki, Aomori 036-8561, Japan

E-mail: katagata@cc.hirosaki-u.ac.jp

Abbreviations: K, keratin; SCC, squamous cell carcinoma; siRNA, small interfering RNA

Key words: keratin expression, invasion assay, RNA interference, human cultured tumor cell lines and urinary bladder carcinoma, as well as in squamous cell carcinoma (SCC). In fact, 28 type I Ks and 26 type II Ks as components of intermediate filaments (IFs) are known to be expressed in human epithelial cells (appendage-forming epithelia such as inner hair follicles) and structural epithelial cells (hard structures and appendages such as hair, nail and tongue). Moreover, Ks are differentially expressed as specific pairs of type I (smaller and relatively acidic, 40-63 kDa and pI 4.5-5.5) and type II (larger and more basic, 53-67 kDa and pI 4.5-7.5) proteins, both of which are necessary for filament formation: at least one pair of $\mathrm{Ks}$ is always expressed in every epithelial cell (1-3).

The type-specific distribution of IF protein has been increasingly used as the basis for the differential histopathological diagnosis of tumors where morphological criteria have proven to be inconclusive. It has been reported that $\mathrm{Ks}$ are expressed in epidermal melanocytes derived from neural crest cells and neural ectoderm (4,5). The evidence presented above suggests that $\mathrm{K}$ expression may be related to further differentiation in epithelial tissues, and is not derived from original cells or tissues.

In a previous study, we observed a negative correlation between $\mathrm{K}$ expression (the number of Ks expressed) and cell invasion capability in three cultured human adenocarcinoma cell lines (6). The number of expressed Ks increases inversely with the invasive index as follows: SW-13 (7) (K number, 2.5; invasion index, 1.781), RERF-LC-OK (K number, 6.5; invasion index, 1.219), and HEC-1 (8) (K number, 7.5; invasion index, 0.562). That is, the number of expressed $\mathrm{Ks}$ has been suggested to reduce the cell invasion capability of epithelial adenocarcinoma cells (6). Motility and invasion assays were conducted to investigate the relative contributions of these changes in the K subunit constituents among the three cultured adenocarcinoma cell lines used.

To clarify the correlation between $\mathrm{K}$ epxression and its involvement in cell invasion activity, we performed RNA interference (RNAi) K knockdown experiments using the SCC cell line, T24, and the adenocarcinoma cell line, HEC-1. In general, a single strand of 19-21 nucleotide small interfering RNA (siRNA), which is complementary to mRNA, yields target-specific mRNA cleavage by the RISC complex and induces specific gene silencing. 
Analytical experiments to examine siRNA and cell invasion capability were conducted using metastatic epithelial tumor cells [SCC and malignant melanoma (MM)] to determine whether Ks play an essential role in the above phenomena.

\section{Materials and methods}

Cell culture. The cultured human tumor cell lines SW-13 (7), HEC-1 (8), HSC-1 (9), HSC-5 (10), DJM-1 (11) and T24 (12) were supplied by the Health Science Research Resources Bank, Osaka, Japan. These cell lines were maintained in culture for no longer than 2 weeks in each set of experiments to ensure that their phenotype would not change as a result of prolonged in vitro passage. The cultured cells were grown as monolayers by passage at semi-confluent stage in culture dishes $\left(78.5 \mathrm{~cm}^{2}\right.$; Greiner Bio-One $\mathrm{GmbH}$, Frickenhausen, Germany) at $37^{\circ} \mathrm{C}$ in a humidified incubator with $5 \% \mathrm{CO}_{2} / 95 \%$ air. Each cell line was then plated at approximately $1.5 \times 10^{3}$ cells $/ \mathrm{cm}^{2}$ in minimal essential medium (MEM; for T24, RERF-LC-OK and HEC-1), Dulbecco's modified Eagle medium (DMEM; for HSC-1, HSC-5 and DJM-1), and Leibovitz's L-15 medium (for SW-13) supplemented with $10 \%$ fetal calf serum (FCS), penicillin (100 units $/ \mathrm{ml}$ ), streptomycin $(50 \mu \mathrm{g} / \mathrm{ml})$ and amphotericin B $(2.5 \mu \mathrm{g} / \mathrm{ml})$. Cell numbers were determined using an automated cell counter (Countess; Invitrogen Corp., Carlsbad, CA, USA).

Western blot analysis. Proteins were extracted from a number of cultured cells using cell extraction buffer containing $50 \mathrm{mM}$ Tris- $\mathrm{HCl}(\mathrm{pH} 7.5) / 150 \mathrm{mM} \mathrm{NaCl} / 1 \mathrm{mM}$ EDTA/1\% Triton X-100/protease inhibitors (2 mM N-ethylmaleimide, $50 \mathrm{mg} / \mathrm{ml}$ aprotinin, $50 \mathrm{mg} / \mathrm{ml}$ leupeptin and pepstatin) at $4^{\circ} \mathrm{C}$. Following centrifugation, the soluble protein in the extract was quantified according to the method described by Bradford (13). Proteins were separated by SDS-PAGE and then blotted onto PVDFmembranes. The membranes were then blocked inblocking buffer, $0.5 \%$ non-fat dry milk TBST [10 mM Tris (pH 7.8), $150 \mathrm{mM} \mathrm{NaCl}$ and $0.05 \%$ Tween-20] at room temperature for $1 \mathrm{~h}$. Primary antibody was diluted at 1:1000 in the blocking buffer. The membrane was incubated at room temperature for $1 \mathrm{~h}$ with the following antibodies: CAM 5.2 against K8/K18 (Becton-Dickinson, Franklin Lakes, NJ, USA), Ks 19.1 against K19 (Progen Biotechnik GmbH, Heidelberg, Germany), and anti-actin (Thermo Fisher Scientific, Fremont, CA, USA). Membranes were washed four times for 15 min each time with the blocking buffer. The membranes were then incubated with corresponding horseradish peroxidase-conjugated secondary antibodies in the blocking buffer at room temperature for $1 \mathrm{~h}$ and washed two times for 15 min each with the blocking buffer. Antigen-antibody complexes were detected with a chemiluminescence method using an enhanced chemiluminescence (ECL) Plus kit (Amersham Biosciences Co., Buckinghamshire, UK). They were then exposed to X-ray film (Fuji Photo Film Co. Ltd., Tokyo, Japan). To evaluate the $\mathrm{K}$ index (number of $\mathrm{K}$ subunits expressed in each cultured cell line), numerous types of $\mathrm{K}$ monoclonal antibodies were used for western blot analysis. In addition, 2D-PAGE was conducted as described previously $(6,14)$.

Cell migration in two cultured cell lines. Two human tumor cell lines (SCC and adenocarcinoma) were treated with
trypsin/EDTA. The obtained cells were adjusted to $1 \times 10^{5}$ cells/ $\mathrm{ml}$ in $0.1 \%$; each medium contained $10 \%$ FCS. Each prepared cell suspension $\left(5 \times 10^{4}\right.$ cells $\left./ 0.5 \mathrm{ml}\right)$ was set to a Falcon cell companion plate (inner chamber, $8 \mu \mathrm{m}$ pore size membrane, 24 inserts each, BD Biocoat Matrigel Invasion chamber; Becton-Dickinson Labware, Bedford, MA, USA) using four wells for each sample. In addition to Falcon TC companion plates (outer chamber), $0.7 \mathrm{ml}$ of tenascin $(100 \mathrm{ng} / \mathrm{ml})$ migration enhancement factor was added. As a negative control, each medium $+0.1 \%$ FCS only was added to a Falcon TC companion plate. The invasion chambers were placed in a $5 \% \mathrm{CO}_{2}$ incubator at $37^{\circ} \mathrm{C}$ for $24 \mathrm{~h}$. The cells that had migrated into the Matrigel matrix were counted using a hemocytometer after staining with hematoxylin and eosin. The percentage of invasion and invasion index were derived using the following formulae:

Mean no. of cells invading through the Matrigel insert membrane

$$
\begin{aligned}
& \% \text { invasion }=\frac{\text { Mean no. of cells migrating through }}{\text { the control insert membrane }} \times 100 \\
& \text { Invasion index }=\frac{\% \text { Invasion test cells }}{\% \text { Invasion control cells }} \times 100
\end{aligned}
$$

siRNA-mediated knockdown of K8, K18 and K19. RNAi duplexes were synthesized using a Silencer siRNA Construction Kit (Ambion Inc., Austin, TX, USA) in accordance with the manufacturer's instructions. The siRNAs matching selected regions of each $\mathrm{K}$ sequence were synthesized by Ambion with the siRNA Target Finder. The sequences were subjected to BLAST search to ensure target specificity. The siRNA sequences of the three Ks were as follows: K8 (KRT8-sense), 5'-AACT TGGTCTCCAGCATCTTGCCTGTCTC-3'; K8 (KRT8antisense), 5'-AACAAGATGCTGGAGACCAAGCCTGTC TC-3'; K18 (KRT18-sense), 5'-AAGTAGGCCTTTTACTT CCTCCCTGTCTC-3'; K18 (KRT18-antisense), 5'-AAGAGG AAGTAAAAGGCCTACCCT-GTCTC-3'; K19 (KRT19-sense), 5'-AACTGCATGGTTAGCTTCTCGCCTGTCTC-3'; K19 (KRT19-antisense), 5'-AACGAGAAGCTAACCATGCAGCC TGTCTC-3'.

Control siRNA was designed corresponding to a non-target sequence similar to those of the three K siRNAs. Cells used for knockdown experiments (T24 and HEC-1) were plated in $10 \mathrm{~cm}$ culture dishes and transfected using Lipofectamine ${ }^{\mathrm{TM}}$ RNAiMAX (Invitrogen Corp.) to a final concentration of $10 \mathrm{nM}$. Following transfection, the cells were incubated for $72 \mathrm{~h}$. Then they were harvested for western blot analysis.

\section{Results and Discussion}

Correlation between keratin expression and cell invasion activity. The contents of Ks prepared from each cultured cell line were confirmed by western blot analysis using various types of anti-K antibodies (6) following SDS-PAGE. The $\mathrm{K}$ index was calculated as described above for each cell line using the following criteria, as shown in Table I: positive band, $1(\mathrm{O})$; intermediate band, $0.5(\triangle)$; negative band, $0(\times)$. 
Table I. Keratin expression in the two cultured cell lines using western blot analysis.

\begin{tabular}{|c|c|c|c|c|c|c|c|c|c|c|c|c|c|c|}
\hline & $\mathrm{K} 1$ & K5 & K6 & K7 & K8 & K10 & K13 & K14 & K16 & K17 & K18 & K19 & $\mathrm{V}$ & Keratin index \\
\hline \multicolumn{15}{|l|}{$\mathrm{SCC}$} \\
\hline HSC-1 & $x$ & O & $x$ & O & O & - & O & O & O & O & O & $\triangle$ & $\times$ & 8.5 \\
\hline HSC-5 & O & 0 & $\triangle$ & O & O & - & O & O & O & 0 & O & O & $x$ & 10.5 \\
\hline DJM-1 & O & $x$ & O & 0 & 0 & - & $x$ & $x$ & 0 & $x$ & $\triangle$ & $\triangle$ & $x$ & 6.0 \\
\hline $\mathrm{T} 24$ & $x$ & O & $\Delta$ & O & O & - & $\triangle$ & O & O & O & O & O & $x$ & 9.0 \\
\hline \multicolumn{15}{|l|}{ Adenocarcinoma $^{\mathrm{a}}$} \\
\hline RERF-LC-OK & 0 & $\triangle$ & $\triangle$ & 0 & 0 & - & $\triangle$ & 0 & 0 & 0 & 0 & $\times$ & O & 7.5 \\
\hline HEC-1 & O & $\triangle$ & $\triangle$ & O & O & - & 0 & $\triangle$ & O & O & ○ & o & 0 & 8.5 \\
\hline SW-13 & O & $x$ & $\triangle$ & $\times$ & $\triangle$ & - & $x$ & $x$ & O & 0 & $x$ & $x$ & $\Delta$ & 3.0 \\
\hline
\end{tabular}

${ }^{\text {a} Y a m a s h i t a ~ e t ~ a l ~(6) . ~ K, ~ k e r a t i n ; ~ V, ~ V i m e n t i n ; ~ S C C, ~ s q u a m o u s ~ c e l l ~ c a r c i n o m a . ~(O), ~ p r e s e n t ; ~}(\triangle)$, faint; ( $\times$ ), absent; (-), not detected. Keratin index was calculated as $1(\mathrm{O}), 0.5(\triangle)$ and $0(\times)$ points which are evaluated with western blot analysis data.

Table II. Migration activity and keratin expression index in the two cultured epidermal carcinoma cell lines.

\begin{tabular}{|c|c|c|c|c|c|c|}
\hline Cell line & $\begin{array}{l}\text { (A) NC migrated } \\
\text { cell no. }\end{array}$ & $\begin{array}{l}\text { (B) } \mathrm{NC} \text { cell } \\
\text { invasion }(\%)\end{array}$ & $\begin{array}{l}\text { (C) Treated } \\
\text { migrated cell no. }\end{array}$ & $\begin{array}{l}\text { (D) Tested cell } \\
\text { invasion }(\%)\end{array}$ & $\begin{array}{l}\text { (E) Invasion } \\
\text { index }\end{array}$ & $\begin{array}{l}\text { Keratin } \\
\text { index }^{\mathrm{a}}\end{array}$ \\
\hline \multicolumn{7}{|l|}{$\mathrm{SCC}$} \\
\hline HSC-1 & 4,053 & 8.106 & 5,241 & 10.482 & 1.293 & 8.5 \\
\hline HSC-5 & 2,528 & 5.056 & 2,541 & 5.082 & 1.005 & 10.5 \\
\hline DJM-1 & 2,578 & 5.156 & 4,143 & 8.286 & 1.607 & 6.0 \\
\hline $\mathrm{T} 24$ & 9,899 & 19.798 & 9,778 & 19.556 & 0.988 & 9.0 \\
\hline \multicolumn{7}{|l|}{ Adenocarcinoma $^{\mathrm{b}}$} \\
\hline RERF-LC-OK & 1,005 & 2.01 & 1,116 & 2.452 & 1.219 & 7.5 \\
\hline HEC-1 & 900 & 1.80 & 508 & 1.016 & 0.564 & 8.5 \\
\hline SW-13 & 515 & 1.03 & 917 & 1.834 & 1.781 & 3.0 \\
\hline
\end{tabular}

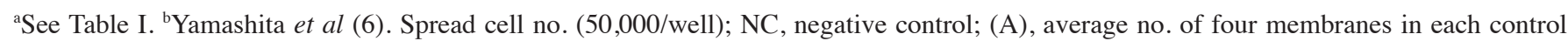
sample; (B), (A)/apread cell no. x100 (\%); (C), average no. of four membranes in each tested sample; (D), (C)/spread cell no. x100 (\%); (E), (D)/(B). SCC, squamous cell carcinoma.

Furthermore, the cell invasion index was calculated from the number of cells passing through the bottom membrane of the inner chamber, as described in Materials and methods and shown in Table II. In both types of tumor cell line, a higher $\mathrm{K}$ expression was associated with low invasion activity (T24, HSC-5 and HEC-1) as shown in Table II. These phenomena suggest that the $\mathrm{K}$ subunit may be fixed firmly in an intercellular construct and that it may be related to tumor cell stability. That is, the $\mathrm{K}$ expression (and the number of $\mathrm{Ks}$ expressed) in each cell line may be related to the degree of invasion activity based on the data in Tables I and II. The correlation co-efficients $\left(\mathrm{R}^{2}\right)$ were calculated as shown in Fig. 1 (adenocarcinoma, $\mathrm{R}^{2}=0.9074$; $\mathrm{SCC}, \mathrm{R}^{2}=0.993$ ). These data demonstrated an excellent correlation in SCC and adenocarcinoma cells. As K expression may be closely related to cell invasiveness, RNAi experiments were performed to confirm the essential participation of K itself. T24 and HEC-1 were employed in the RNAi experiment as typical SCC and adenocarcinoma tumor cells, respectively.
Confirmation of $K$ expression in metastatic cells by siRNA. Among the $\mathrm{K}$ molecules, K8 and K18 were first identified in the liver and as markers of mouse embryonic carcinoma and embryonic stem cell differentiation $(15,16)$. As K19 is a $\mathrm{K}$ tumor marker, we conducted siRNA experiments for the above three Ks in SCC and adenocarcinoma cell lines. Two experiments (Fig. 2) were carried out independently, and the relative value of control siRNA was adjusted with each control siRNA and actin internal control.

In T2 4 cells, K8 siRNA caused a decrease of approximately $90-95 \%$ in K18 and K19 expression compared with control siRNA (Fig. 2A). On the contrary, siRNAs of K18 and $\mathrm{K} 19$ had no significant effect on the expression of K8, and the rate of $\mathrm{K}$ reduction was approximately $20-60 \%$, as shown in Fig. 2B (left section reacted with anti-K8 antibody). These results suggest that K8 (type II keratin) may lead to the formation of K8/K18 and K8/K19 filaments. Furthermore, our data support the suggestion of Giudice and Fuchs, namely the induction of a type I K by a type II gene (17). 
A

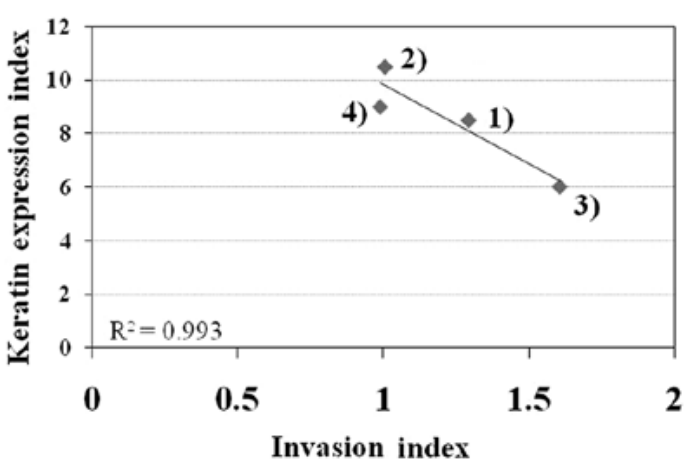

B

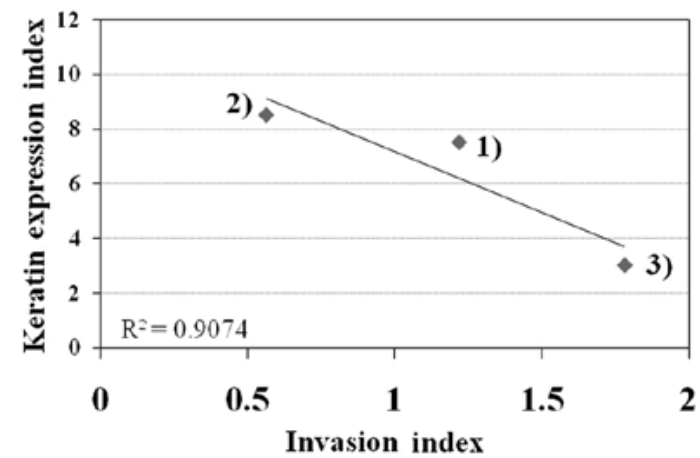

A) SCC: 1) HSC-1, 2) HSC-5, 3) DJM-1, 4) T24

B) Adenocarcinoma: 1) RERF-LC-OK, 2) HEC-1, 3) SW-13

Figure 1. Correlation between keratin expression index and cell invasion activity. (A) SCC; 1) HSC-1, 2) HSC-5, 3) DJM-1, 4) T24. (B) Adenocarcinoma; 1) RERF-LC-OK, 2) HEC-1, 3) SW-13. $\mathrm{R}^{2}$, correlation coefficient. SCC, squamous cell carcinoma.

A

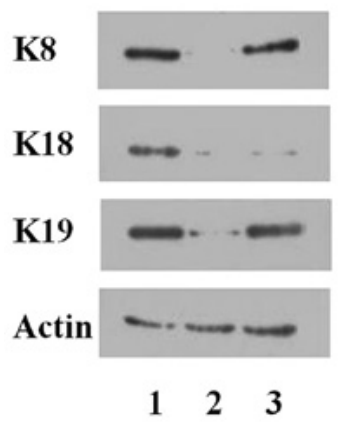

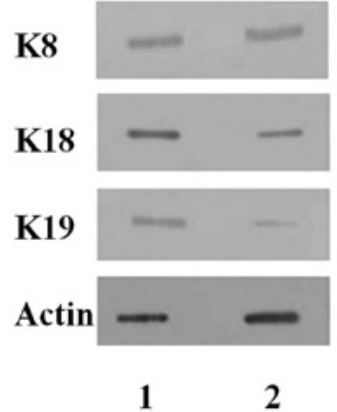

B

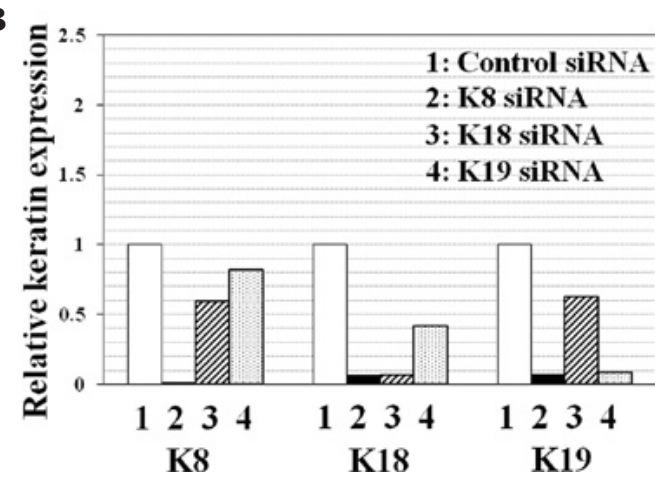

Figure 2. Downregulation of keratin (K) in T24 bladder tumor cells. (A, left panel) K8, K18 and K19 expression in T24 cells treated with K8 and K18 siRNAs was detected by western blot analysis. Actin was used as the internal control. 1, control siRNA; 2, K8 siRNA; 3, K18 siRNA. (A, right panel) K19 expression in T24 cells treated with K19 siRNA was detected by western blot analysis. (B) Relative K expression compared to the control siRNA. As in (A), experiments were carried out independently, relative data were adjusted with the values for control siRNA and actin. 1, control siRNA; 2, K8 siRNA; 3, K18 siRNA; 4, K19 siRNA. siRNA, small interfering RNA.

HEC-1 (8), a cultured adenocarcinoma cell line, is characterized by low invasion activity and a high number of Ks expressed in the three types of cultured adenocarcinoma cells (Fig. 1A). In the RNAi experiments, K8 siRNA resulted in the downregulation of K18 and K19, and K18 siRNA led to the upregulation of K19 peptide ( 2.3-fold) (Fig. 3A and B). However, the K18 peptide was not detected even with K8 siRNA and K19 siRNA. The reasons for these observations were unclear, but these phenomena were reproducible.

In addition, K19 siRNA completely downregulated K18 expression. These results suggest that K18 replaces K19 to form $\mathrm{K} 8 / \mathrm{K} 18$ or K8/K19 filaments. However, the reverse phenomenon (from K19 to K18) may not occur. Under the above conditions, a single $\mathrm{K} 8$ peptide may have an affinity with the other type I-K peptides until upregulation of K18 or K19 finished, as described in mouse embryos (18).

The comparison of cell invasion activity by RNAi-induced cells. To further demonstrate the essential role of Ks in cell invasion activity, the invasion activity of cells treated with $\mathrm{K}$ siRNAs was analyzed using a Falcon cell companion plate as described in Materials and methods. In the T24 cell analysis, two separate experiments (first, K8 and K18 siRNAs; second, K19 siRNA) were carried out independently, and the data were adjusted with each control siRNA. Each sample was added to four wells to obtain more reliable data, and the results were reproducible. K8 siRNA was most effective against cell invasion, and the order of the others was K8>K19>K18 (Table III and Fig. 4A). The above data were also estimated to some degree in a decreased rate of expressed Ks in Fig. 2B.

On the contrary, the order of the degree of influence on HEC-1 cell invasion activity was very distinct; however, the order of relative invasion activity $(\mathrm{K} 8>\mathrm{K} 19>\mathrm{K} 18)$ was similar to that of T24 cells as shown in Fig. 4A and B. Moreover, the relative invasion activity in cells treated with K8 siRNA was approximately two-fold higher than in cells treated with control siRNA (Table III and Fig. 4B). Furthermore, K19 siRNA also induced notably higher activity than K18 siRNA. In addition, K19 downregulation has been suggested to increase the invasive potential, as described in oral SCC cells (19). The above data indicated that the order of HEC-1 cell invasion activity was the same as that of $\mathrm{T} 24$ cells $(\mathrm{K} 8>\mathrm{K} 19>\mathrm{K} 18)$ as shown 
Table III. The relative invasion activity in T24 and HEC-1 cells treated with keratin siRNAs.

\begin{tabular}{|c|c|c|c|c|c|c|}
\hline Cell line & $\begin{array}{l}\text { (A) NC migrated } \\
\text { cell no. }\end{array}$ & $\begin{array}{l}\text { (B) NC cell } \\
\text { invasion }(\%)\end{array}$ & $\begin{array}{l}\text { (C) Treated } \\
\text { migrated cell no. }\end{array}$ & $\begin{array}{l}\text { (D) Tested cell } \\
\text { invasion }(\%)\end{array}$ & $\begin{array}{l}\text { (E) Invasion } \\
\text { index }\end{array}$ & $\begin{array}{c}\text { Relative } \\
\text { value }\end{array}$ \\
\hline \multicolumn{7}{|l|}{$\mathrm{T} 24$} \\
\hline Control siRNA & 2,467 & 9.87 & 2,318 & 9.27 & 0.940 & 1 \\
\hline K8 siRNA & 2,380 & 9.52 & 2,815 & 11.26 & 1.183 & 1.259 \\
\hline K18 siRNA & 2,625 & 10.50 & 2,719 & 10.88 & 1.036 & 1.102 \\
\hline Control siRNA & 565 & 2.26 & 434 & 1.74 & 0.768 & 1 \\
\hline K19 siRNA & 269 & 1.08 & 234 & 0.94 & 0.870 & 1.132 \\
\hline \multicolumn{7}{|l|}{ HEC-1 } \\
\hline Control siRNA & 5,882 & 11.76 & 5,491 & 10.98 & 0.934 & 1 \\
\hline K8 siRNA & 1,272 & 2.54 & 2,325 & 4.65 & 1.831 & 1.960 \\
\hline K18 siRNA & 1,366 & 2.73 & 1,320 & 2.64 & 0.967 & 1.035 \\
\hline K19 siRNA & 2,351 & 4.70 & 3,554 & 7.11 & 1.513 & 1.620 \\
\hline
\end{tabular}

Spread cell no. (50,000/well); NC, negative control; (A), average no. of four membranes in each control sample; (B), (A)/spread cell no. x100 (\%); (C), average no. of four membranes in each tested sample; (D), (C)/spread cell no. x100 (\%); (E), (D)/(B). K, keratin; siRNA, small interfering RNA.
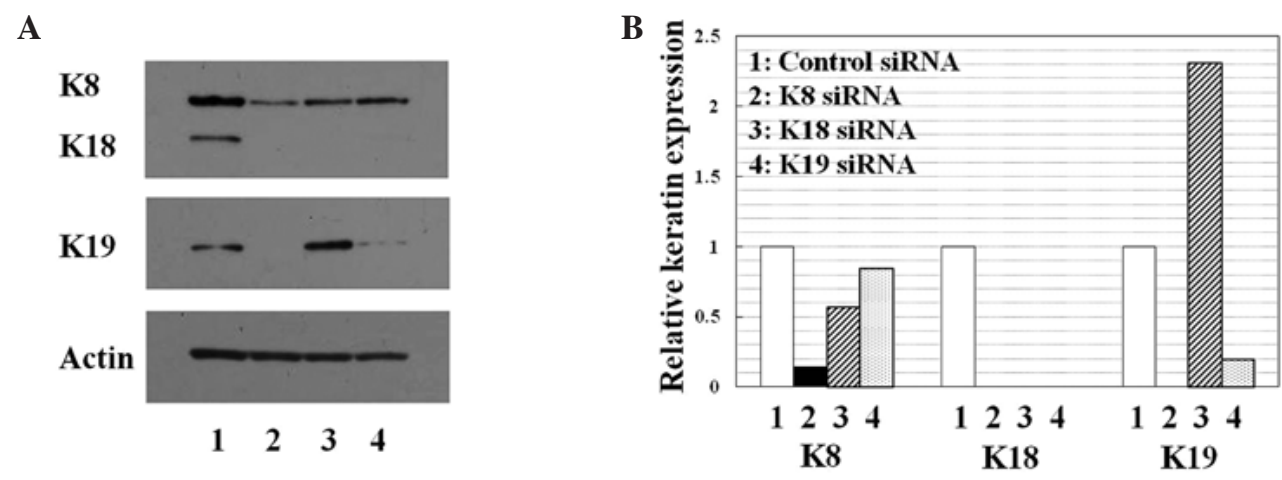

Figure 3. Downregulation of Ks in HEC-1 adenocarcinoma cells. (A) K8, K18 and K19 expression in HEC-1 cells treated with K8, K18 and K19 siRNAs was detected by western blot analysis. Actin was used as the internal control. 1, control siRNA; 2, K8 siRNA; 3, K18 siRNA; 4, K19 siRNA. (B) Relative K expression compared to the control siRNA. 1, control siRNA; 2, K8 siRNA; 3, K18 siRNA; 4, K19 siRNA. K, keratin; siRNA, small interfering RNA.
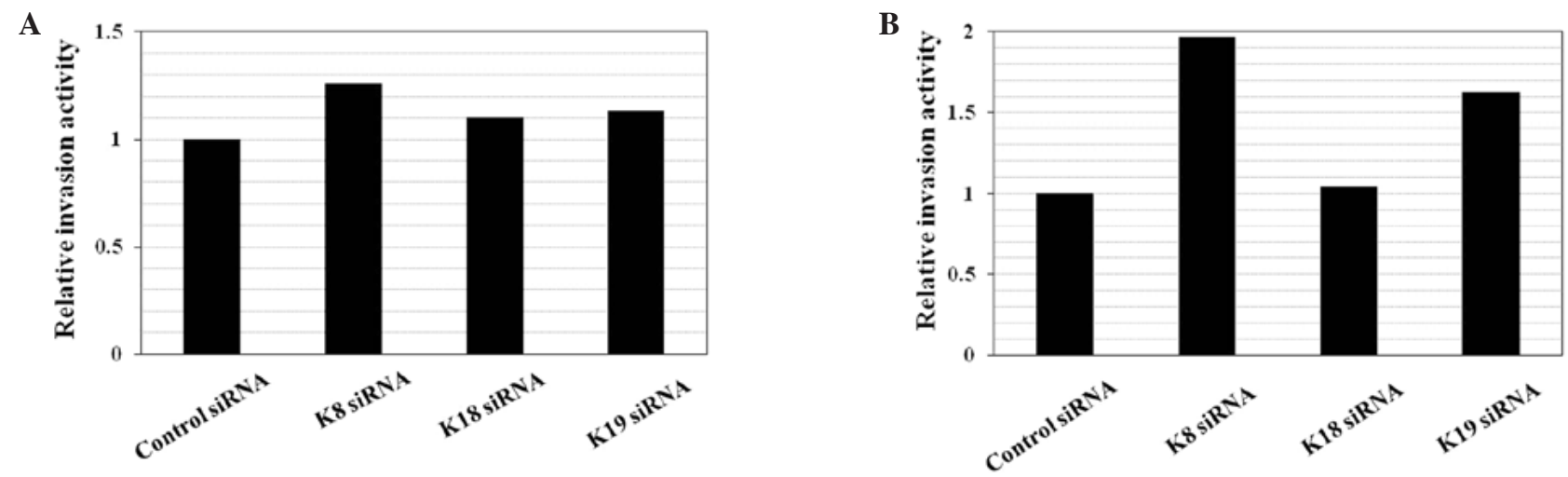

Figure 4. The relative invasion activities of the two types of cultured cells treated with each siRNA. (A) T24 cultured cells. (B) HEC-1 cultured cells. K, keratin; siRNA, small interfering RNA.

in Fig. 4A and B. These results showed that no K filaments formed in the treated cells and that cell invasion activity increased approximately two-fold compared to that in the control cells.
The present study clarifies the correlation between $\mathrm{K}$ expression and cell invasion activity in cultured SCC and adenocarcinoma cell lines. The correlation was dependent on the number and type of Ks expressed, and showed a 
strong correlation co-efficient of approximately $\mathrm{R}^{2}=1$. These results suggest that the presence of $\mathrm{K}$ molecules may be a significant factor in regulating the invasion activity of epithelial tumor cells.

\section{References}

1. Moll R, Franke WW, Schiller D, Geiger B and Krepler R: The catalog of human cytokines: patterns of expression in normal epithelia, tumors and cultured cells. Cell 31: 11-24, 1982.

2. Lane EB: Intermediate filaments. In: Cells. Lewin B, Cassimeris L, Lingappa VR and Plopper C (eds). Jones and Bartlett Publisher, Sudbury, USA, pp411-437, 2006.

3. Magin TM, Vijayaraj P and Leube RE: Structural and regulatory functions of keratins. Exp Cell Res 313: 2021-2032, 2007.

4. Katagata $Y$ and Kondo S: Keratin expression and its significance in five cultured melanoma cell lines derived primary, recurrent and metastasized melanomas. FEBS Lett 407: 25-31, 1997.

5. Bhawan J, Whren K, Panova I and Yaar M: Keratin 16 expression in epidermal melanocytes of normal human skin. Am J Dermatopathol 27: 476-481, 2005.

6. Yamashita M, Takahashi K, Sato M, Otsu K, Hirayama T and Katagata Y: Comparison of keratin expression in cultured human adenocarcinoma cell lines. J Dermatol Sci 55: 59-61, 2009.

7. Leibovitz AL, McCombs WM, Johnston D, McCoy CE and Stinson JC: New human cancer cell culture lines. I. SW-13, small cell carcinoma of adrenal cortex. J Natl Cancer Inst 51: 691-697, 1973.

8. Morinaga M, Yonehara S, Tomita Y and Kumata T: Insensitivity to interreron of two subclones of human endometorial carcinoma cell line, HEC-1. Int J Cancer 31: 21-28, 1993.

9. Kondo $\mathrm{S}$ and Aso K: Establishment of a cell line of human skin squamous cell carcinoma in vitro. Brit J Dermatol 105: 125-132, 1981.
10. Hozumi Y, Kondo S, Shimoura T and Aso K: Human squamous cell carcinoma from skin: establishment and characterization of a new cell line (HSC-5). J Dermatol 17: 143-148, 1990.

11. Kitajima Y, Owada MK, Fujisawa Y, Seishima M, Yaoita H, Hirako Y and Owaribe K: A hemidesmosomal transmembrane collagenous molecule, the $180-\mathrm{kDa}$ bullous pemphigoid antigen (BPAII), is phosphorylated with 12-O-tetradecanoylphorbol-13acetate in a human squamous cell carcinoma cell line (DJM-1). Epithelial Cell Biol 4: 70-75, 1995.

12. O'Toole CM, Povev S, Hepburn P and Franks LM: Identity of some human bladder cancer cell lines. Nature 301: 429-439, 1983.

13. Bradford MM: A rapid and sensitive method for the quantitation of microgram quantities of protein utilizing the principle of protein-dye binding. Anal Biochem 72: 248-254, 1976.

14. Katagata Y, Takeda H, Ishizawa T, Hozumi Y and Kondo $\mathrm{S}$ : Occurrence and comparison of the expressed keratins in cultured human fibroblasts, endothelial cells and their sarcomas. J Dermatol Sci 30: 1-9, 2002.

15. Franke WW, Denk H, Kalt R and Schmid E: Biochemical and immunological identification of cytokeratin proteins present in hepatocytes of mammalian liver tissue. Exp Cell Res 131: 299-318, 1981.

16. Oshima RG: Identification and immunoprecipitation of cytoskeletal proteins from murine extra-embryonic endodermal cells. J Biol Chem 256: 8124-8133, 1981.

17. Giudice GJ and Fuchs E: The transfection of epidermal keratin genes into fibroblasts and simple epithelial cells: Evidence for inducing a type I keratin by type II gene. Cell 48: 453-463, 1987.

18. Hong Lu, Michael H, Bettina P and Thomas MM: Type II keratins precede type I keratins during early embryonic development. Eur J Cell Biol 84: 709-718, 2005.

19. Crowe DL, Milo GE and Shuler CE: Keratin 19 downregulation by oral squamous cell carcinoma lines increases invasive potential. J Dent Res 78: 1256-1263, 1999. 